\title{
The Application Research of Industrial Engineering Technology in Equipment Maintainability Design \\ Lei GUO ${ }^{1,}$, Xiangqian SHAN ${ }^{1}$, Xiaobo LI ${ }^{1}$, Yu Xiao ${ }^{1}$ \\ ${ }^{1}$ Department of Control Engineering, Armor Technique Institute, Changchun130117, China. \\ aguoleilei_vip@163.com
}

\begin{abstract}
Keywords: Ergonomics industrial engineering technology, maintainability design, virtual maintenance
\end{abstract}

\begin{abstract}
The paper discusses on the industrial engineering technology for weapon equipment's maintainability design, including maintenance standardization flow design based on process analysis, the maintenance operation design based on motion analysis, maintainability index verification based on ergonomics, equipment maintenance mode decision based on value engineering and so on.
\end{abstract}

\section{Introduction}

The maintainability of weapons and equipment, as a design attributes, is necessary to discover the problems exactly through the interaction among the human, equipment, and maintenance tools / facilities [1]. Current equipment maintainability design has been partially based on the virtual prototype, and the virtual maintenance technology increasingly used in equipment maintainability analysis. Such as the use of virtual maintenance for equipment maintainability analysis of qualitative factors, which were considered more Ergonomics factors [2]. On one hand, ensure the equipment parallel design, on the other; provide the direction for early detection of maintainability design defects. Ergonomics is one of the industrial engineering technologies.

Industrial engineering is the study of integrated system design, improvement and installation which considered the human, material, equipment, resources and information actors, it applied natural science such as mathematics, physics, and social science expertise and technology and the design principle and methods of engineering analysis to determine, predict and evaluate the results that the system can receive[3].In fact, under the environment of virtual maintenance, industrial engineering technology can be widely applied in the process of maintainability design of weapon and equipment. For example, the standardization design of maintenance flow, the maintenance operation design, the maintainability index verification, as well as the maintenance mode decision. It discusses the significance and reference value for the development of equipment maintenance work in design stage. And has a significant and important reference value for equipment maintainability design.

\section{The maintenance standardization flow designated on process analysis}

The Current maintenance standard generally laid stress on equipment maintenance quality, but for the maintenance process, the co-ordination between the various types of work, the operation of maintenance personnel, it does not have a formulated and standard working process. It often leads to problems occurred in the maintenance activity. For a new developed equipment, the failure point, causes and treatment methods are all experiences that you can follow [4].Based on the early research diagnosis, we should find out the maintenance events that can solve it, give the maintenance operation with the process description, and then apply the ECRS method (erasing, combining, rearranging and simplifying) to optimize the maintenance process, so as to get the best maintenance workflow. Maintenance workflow standardization design makes the maintenance procedures and training material development could be carried out in the initial stage of maintainability design, it will greatly improving the indemnificatory force of equipment. 


\section{The maintenance operation design based on motion analysis}

The Motion analysis is the study on the decomposition of the action, analyzing the relationship between each motion elements with the other, in order to eliminate waste, makes the motion more simplified, more reasonable. The virtual maintenance simulation must have a reasonable description of the maintenance guide. For a maintenance operation process, first we should decompose the maintenance process. A maintenance task contains several maintenance operations, a maintenance operation contains several maintenance motions, and each maintenance motion is combining by several basic maintenance motion elements. The basic element including such as go a step, grab tool, and place, carry, handling etc, these basic element can called by the corresponding action function from the motion database. In accordance with the inverse process of decomposition of the maintenance process, we can fulfill the dynamic simulation of equipment maintenance. Through the dynamic simulation of movement analysis, instantaneous motion analysis, and the micro-motion analysis to improve the operations, eliminates redundancy, we can achieve the optimization of maintenance operations.

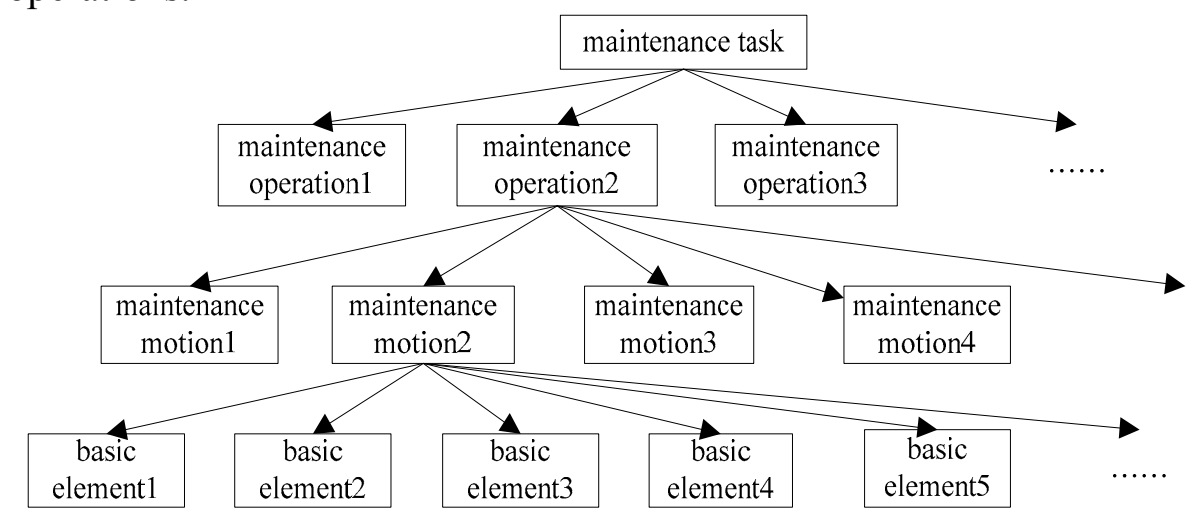

Fig. 1 Decomposition of maintenance motion

\section{Maintainability Index Verification of qualitative factors based on Ergonomics}

Ergonomics, aimed for the purpose of the human safety, health, comfort, based on the human physiological and psychological characteristics, analyzing the interaction between man, machine and environment to design the man-machine-environment systems [5]. During the design phase, develop maintainability index verification of qualitative factors, the difficulty has two aspect. First, the human factor cannot be included to the maintainability analysis, the virtual human technology solved this problem; the second is lack of reliable prototype, the emergence of virtual prototype solved this problem. Based on ergonomics, the maintainability index verification of qualitative factors main considered of whether the equipment maintainability design meet the accessibility, visibility, force analysis of maintenance posture, fatigue degrees and security[6]. Its ideas is: import virtual human, virtual prototype to virtual environment, Through the interaction with the digital prototype for dynamic testing, maintenance personnel are guided to analyze the maintenance parts, such as whether there is sufficient space, proper size and location, repair parts are visible, anywhere needed for installation whether the space is enough to operate, and so on. It can give a valuable outcome, provided all aspects of evaluation such as visibility, accessibility, maintenance staff's stress, fatigue and safety. Figure 2 shows the maintainability qualitative parameters validation process based on ergonomics. Figure 3 shows a method of reach ability verification and implementation. Figure 4 reflect in the operation, the stress analysis of virtual human's right arm, through the simulation of the whole process, we can draw the result whether the virtual human is fatigue. (Figure 5) 


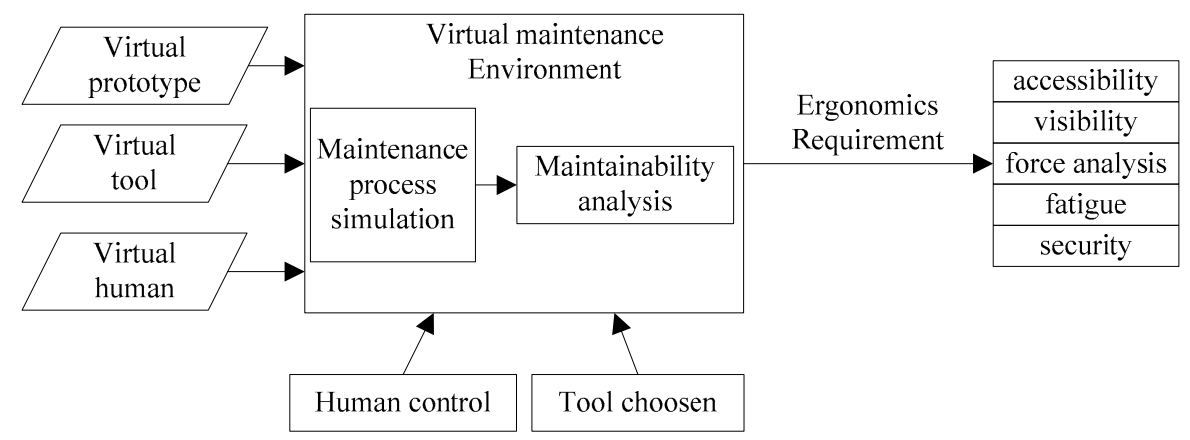

Fig. 2 Maintainability index verification of qualitative factors based on ergonomics

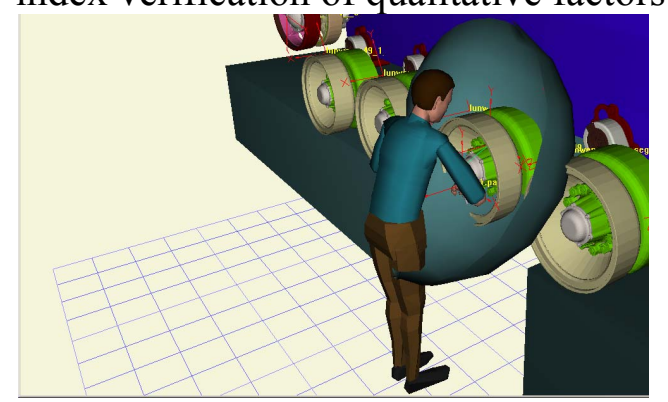

Fig. 3 Ergonomics-based accessibility validation

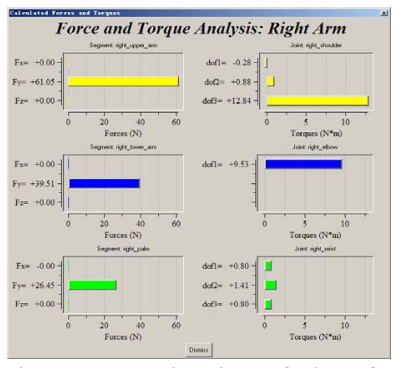

Fig. 4 Analysis of the force on the right arm

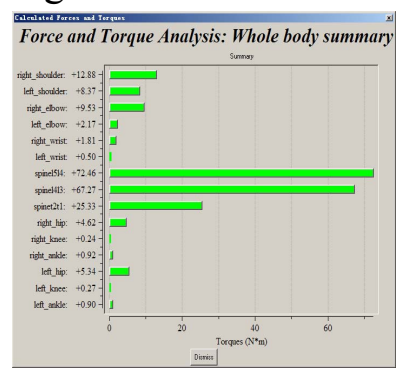

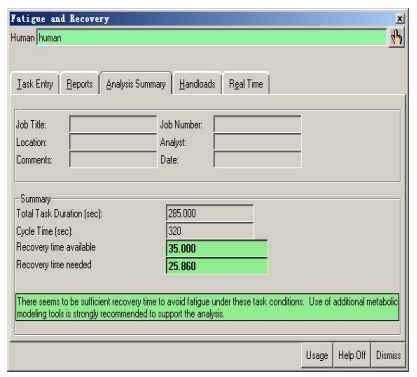

Fig. 5 Fatigue analysis results

\section{Maintainability quantificational factors validation based on Standardization of maintenance motion}

Equipment maintainability quantificational factors validation means at the natural fault or simulation conditions, according to research data, after testing, analyzing and assessing, to make sure the repair work Can be completed within the stipulated time[7]. Mean time to repair (MTTR) is the most commonly used quantitative maintainability verification parameters. In virtual environments, according to standards of maintenance therblig database, though the repair dynamic simulation, we can generate the time of equipment maintenance. The time of maintenance therblig should consider the maintenance environment, the maintenance staff's skill level [8]. Based on equipment maintenance simulation time, we can obtain maintenance simulation time, provide reliable sample to validate the quantitative index.

\section{Selection of equipment maintenance mode based on value engineering}

Value engineering is, at the lowest total cost, focus on functional analysis, and an organized activity that reaches the necessary function of products or operations [9]. For equipment maintenance, it can not be separated by technology and economy. Therefore, use the value engineering, based on best "value", we can choose the best maintenance mode.

Weapon equipment maintenance mood includes correction maintenance, preventive maintenance, condition based maintenance, reformative maintenance etc [10], the maintenance mode "value" targets, included the maintenance mode utility (acceptable), added value (high quality, predictable),cost(shorter average maintenance time, sufficient spare parts stock ), security, and other factors. Its analysis process as follows: 


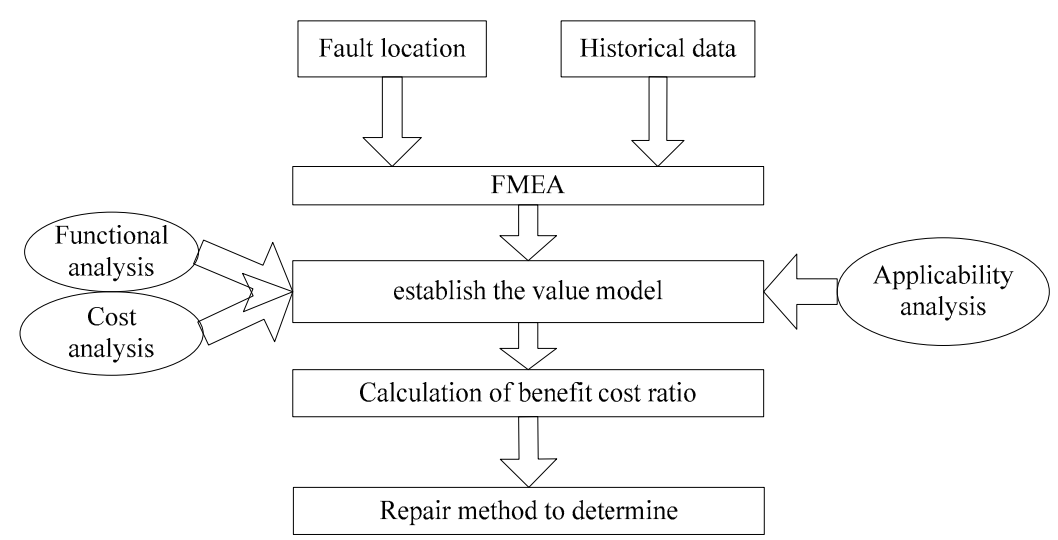

Fig. 6.Maintenance mode selection process

\section{Conclusion}

The industrial engineering technology used in the maintainability design of weapon and equipment, reflecting the traditional maintainability design work has room for improvements in the maintenance standardization flow design, optimization of maintenance operations, maintainability index verification, as well as maintenance mode selection. Industrial engineering technology can provide excellent help. It makes the maintainability design of weapon and equipment more standardization and scientific. Popularized industrial engineering in the field of equipment maintainability design has a bright future. Meanwhile, we should pay attention to the introduction of industrial engineering methods of integrity and avoid making only partial details of renovation.

\section{References}

[1]Xu Da,Guo Lei,Zhang ying,Wang Zhongsheng. The research of virtual human technology in maintainability analysis of weapons and equipment $[\mathrm{J}]$. Proceedings of the $9^{\text {th }}$ international conference on computer aided industrial design \& conceptual design, 2008, 11 332-334

[2]Zeng Yi. Reachability analysis and evaluation technology based on Maintainability Design [D]. Changsha: The National Defense Science and Technology University, 2007, 17-19

[3]Wang Zhijin, Zhou Peng, Han Zhengbiao. Library's management innovation in the perspective of Industrial Engineering [J]. Library Journal 2012, 9:5-6.

[4] Lv Chuan. Maintainability design analysis and verification [M]. Beijing: National Defense Industry Press, 2012, 55-56

[5] Wei Xue, Han Zuhua. Introduction to industrial engineering [M]. Beijing: China Machine Press, 2009, 18-22

[6]Hai Quan,Peng Gaoliang,Liu Wenjian. Research on the maintainability information model based on VR [J]. Aeta armamentaria, 2010, 31(7):97-100

[7]Li Jia. Research on the maintainability verification system of ship based on virtual reality technology [J].Chinese Journal of Ship Research, 2008, 3(2):72-73

[8]Gao mingjun,Hao Jianping. A new maintainability analysis method -maintenance trouble analysis [J], Journal of Ordnance Engineering College, 005, 17(4):72-73

[9]Cai Xin. Research on business process optimization based on Value Engineering [M]. Jinan: Shandong University, 2011, 6-9

[10] Gan Mao Zhi. Maintainability design and verification [M]. Beijing: National Defense Industry Press, 1995 